\title{
Arrhenius Accelerated Life Test for Luminary Life of High Bright Light Emitting Diodes
}

\author{
Mahesh Edirisinghe ${ }^{*}$, Parinda Rathnayake \\ Department of Physics, University of Colombo, Colombo 03, Sri Lanka \\ *E-mail address: mahesh@phys.cmb.ac.lk
}

Keywords: HBLED; Arrhenius model; HBLED lifespan; luminary life

\begin{abstract}
The High Bright Light Emitting Diodes (HBLEDs) generally having long life but very often its actual life is different from vendor's specification. Vendors do not specify the failure criteria for their products but it may vary from $50 \%$ to $70 \%$ light output maintenance. Further time to test such a quantity takes too long under normal conditions. Longer time consumption for evaluation of such a quantity may not useful in mass production process of HBLEDs. The present study describes the determination of the useful lifetime of 1-W HBLEDs using Arrhenius Accelerated Life Test Model with the modeling parameter as the junction temperature. Failure criterion was chosen as $70 \%$ light output maintenance while two stress levels were selected as $90{ }^{\circ} \mathrm{C}$ and $110{ }^{\circ} \mathrm{C}$ and as recommended by IES LM-80-08 standard. Furthermore, forward voltage of the HBLED was used to determine junction temperature of the diode which is a critical parameter for this study. Moreover, junction temperature of the HBLED recognized as the most critical factor for degrades the lifespan. The Arrhenius Model is based on the junction temperature and activation energy parameters. The activation energy and the scaling factor were found to be $1.31 \mathrm{eV}$ and $6.86 \times 10^{-17}$ hours respectively. HBLED junction temperature under room temperature $\left(23^{\circ} \mathrm{C}\right)$ was found to be $55.72{ }^{\circ} \mathrm{C}$. Finally the $70 \%$ luminary life time of $1-\mathrm{W}$ HBLEDs under these conditions was found to be 8,344 hours.
\end{abstract}

\section{INTRODUCTION}

Nowadays, high bright light emitting diodes (HBLEDs) are dominating over standard LEDs and have gained widespread. Moreover, special deposition techniques have made possible, LEDs with much higher brightness (HBLEDs) than traditional devices. As the name suggests HBLEDs offer much higher levels of luminosity than the standard LEDs. In view of their performance HBLEDs are now entering many areas where other technologies had reigned supreme before. This opens up many new applications such as backlighting for displays, automotive lighting and new consumer products like flash for camera phones or compact projectors. It is well aware that HBLEDs have a number of advantages over the standard LEDs such as higher brightness, longer life span, and more importantly it is be compatible with lead-free processing.

However, as reported by [1] and complaints made by the significant number of consumers, HBLEDs have lower luminary life than that of its specified value by the manufacturer. More precisely the real fact is that the light output of HBLED decreases dramatically over time. Besides there is a conflict between standards for boundary mark between the sufficient light level and insufficient light level. This should vary according to the application. For example light level which is suitable to general illumination may not sufficient for the applications in medical field. Nevertheless still a proper standard for such boundary value is in developing stage [2]. Some newly stipulated standards like IES LM-80-08 recommend using 70\% luminary maintenance as a standard to measure luminary life time but still, manufacturing industry widely use $50 \%$ luminary maintenance as their own standard [3]. LM-80-08 refers to a method for measuring the luminary life time of solid-state lighting sources, which includes HBLEDs. Before the introduction of LM-80, and even at present, LED bulb manufacturers normally rated their products on $50 \%$ degradation but 
in practice this illumination is not sufficient even for general illumination. They report lumen maintenance data using their own disparate and varied systems. Further, time taken to determine luminary life of HBLED bulbs using standard way of keep the bulbs on continuous operating is time consuming, costly and tedious work. It requires long time observation and much larger samples to get sufficiently accurate result. Moreover, there is high likelihood of failure of life determination test due to product variations. Also, testing under different environments may be further difficult and expensive too.

On the other hand, there are many factors cause to degrade the Light output of HBLEDs. As per the information given in [1, 4-10], some of the key factors are; junction temperature, thermal resistance between chip \& surrounding, damage or degradation of the plastic encapsulation material, semiconductor defects, humidity or moisture incursion, voltage or current fluctuation malfunction of components in the electronic driver, damage to the wire bonding that connect the LED \& soldering defects, degradation of the phosphors or secondary illuminator and cyclic effect. Moreover as indicated in [1, 4-10], junction temperature, humidity or moisture inclusion, voltage \& current fluctuation are the most dominant factors that affect the light output of the HBLEDs.

However, as reported in $[1,4,5,9,10]$ junction temperature is the most significant degradation factor among those most dominant factors. This heat generation causes to develop other degradation factors, like semiconductor defects, plastic encapsulation browning, weakening the wire bonding that connect the HBLED. There are two major heat generation sources in the HBLED bulb namely by Joule heating (by all conductions) and by non-radiative recombination (in semiconductor core). But the major contributor is the non-radiative recombination which happens inside the semiconductor die. This non-radiative recombination causes to heat the semiconductor core and as a result junction temperature will increase. HBLED bulb manufactures are greatly concerned on such heating phenomena and still they struggle to manage this excess heat.

Therefore, the objective of this study is to determine luminary life according to the acceptable degradation standard by means of junction temperature as the life time modeling factor resulting an efficient, correct, and economical method.

The study was performed using accelerated life test which predicts time-to-fail as a function of operating stresses and the lifetime determined using light output degradation with time [11]. Out of many acceleration models, Arrhenius Acceleration Model has been chosen as the life time estimation model for this study, due to sample \& facility constraints and according to the failure mechanism [1,4,11-13].

\section{THEORETICAL DEVELOPMENT}

Accelerated life test means that operating a DUT in controlled high stress conditions which produces the same failures that would occur at normal working condition, except that it happen much quicker. Failure may be due to mechanical fatigue, corrosion, chemical reaction, diffusion, migration, etc. These are the same causes of failure under normal stress; but the time scale is simply different. This section explains how the Arrhenius Acceleration Model is used for this study and the theoretical proof that the junction temperature of HBLED can be determined by measuring the potential difference across HBLED.

\subsection{Arrhenius Acceleration Model}

Because of the simplicity and well fitting to the practical data, Arrhenius Acceleration Model is most widely used for accelerated life test estimations. This model predicts how time-to-fail varies with temperature [11]. This empirically based model is known as the Arrhenius equation which is given by equation 1 .

$$
t_{f}=A e^{\left(\frac{\Delta H}{k T}\right)}
$$


Where, $t_{f}$ is time to fail, $A$ is a scaling factor, $\Delta H$ is the activation energy, $k$ is Boltzmann's constant, and $T$ is the absolute temperature measured at the point when the failure process takes place.

Activation energy, which is the critical parameter in the model, depends on physical properties of the material under test. Arrhenius model has been used successfully for failure mechanisms that depend on chemical reactions, diffusion processes or migration processes. This covers many of the non mechanical (or non material fatigue) failure modes that cause electronic equipment failure [11].

In this project the model parameter $T$ was the absolute junction temperature of the HBLED. If the junction temperature of HBLED increases it reduces the time-to-fail or the life time of HBLED. Therefore, the time to fail or mean time to fail (MTTF) was modeled by equation 2 .

$$
\mathrm{MTTF}_{T, x \%}=A e^{\left(\frac{\Delta H}{k T}\right)}
$$

Where, $M T T F_{T, x \%}$ is the mean time to fail at temperature $T$ under failure criteria $x \%$.

It is important to mention at this point that three assumptions were made as given below when applying the Arrhenius equation for this study.

Assumption i All HBLEDs under test were sufficiently homogeneous so that the activation energy $(\triangle H)$ is same for all tested samples (DUT).

Assumption $i$ The failure mechanism under high stresses is same when DUT work under normal condition. That is no new special failure mode arose when DUT work on high temperature conditions.

Assumption iii All temperatures used as high stress is well beyond the normal junction temperature.

\subsection{Relationship of Junction Temperature and Voltage Across the HBLED}

A forward biased pn-junction diode can be characterized by the well known Schottky's diode equation given by equation 3 .

$$
I_{D}=I_{S} e^{\left(\frac{V_{D}}{n k T / q}\right)}
$$

Where, $I_{D}$ is current through diode, $I_{S}$ is the reverse saturation current, $V_{D}$ is voltage difference across HBLED, $n$ is ideality factor, $k$ is Boltzmann's constant, $T$ is absolute temperature of the junction, and $q$ is the charge of an electron.

Moreover, the reverse saturation current $\left(I_{S}\right)$ is given by equation 4 .

$$
I_{S}=S A^{* *} T^{2} e^{\left(\frac{V_{G}}{n k T / q}\right)}
$$

Where, $S$ is the diode junction area, $A^{* *}$ is the Richardson constant, and $V_{G}$ is activation energy for the particular diode which is independent of the temperature.

Equation 4 can be rewrite as $I_{S}=S A^{* *} T^{2}\left[e^{q V_{G}}-e^{n k T}\right]$, for $T \geq 0$. Furthermore for $n$ in the range of 1 to 2 , if $T$ is in the range of $300 \mathrm{~K}$ to $400 \mathrm{~K}$, and since $V_{G}, q, k$, are very small, it can be approximated to; $I_{S} \cong S A^{* *} T^{2}$ where, $\left[e^{q V_{G}}-e^{n k T}\right] \cong 1$. 
Hence equation 3 can be rewrite as given by equation 5 , where constant $c_{1}=S A * *$.

$$
I_{D} \cong c_{1} T^{2} e^{\left(\frac{V_{D}}{n k T / q}\right)}
$$

Equation 5 can represent as; $\ln I_{D} \cong 2 \ln T+\frac{q V_{D}}{n k T}+\ln c_{1}$ and when $I_{D}$ kept constant, and it can be shrink to equation 6 , where constant $c_{2}=\ln I_{D}-\ln c_{1}$.

$$
c_{2} \cong 2 \ln T+\frac{q V_{D}}{n k T}
$$

By differentiating the equation 6 , with respect to $T$, it gives; $0 \cong \frac{2}{T}-\frac{q V_{D}}{n k T^{2}}$. Therefore since, $T \neq 0$, the relationship between potential diffenerce across the diode and the junction temperature is given by equation 7 , where constant $c_{3}=\frac{2 n k}{q}$.

$$
V_{D} \cong c_{3} T
$$

Equation 7 shows that the voltage across diode and the junction temperature have approximately liner relationship which is similar to the constant $\Delta V / \Delta T$ for smaller range of $T$ as reported in [14]. Consequently with the help of experimentaly generated plot of $V_{\mathrm{D}}$ vs $T$, corresponding junction temperature of HBLED can be determined by measuring the voltage across the particular HBLED.

\section{METHODOLOGY}

The experiment was performed on brandnew samples of 1-W HBLEDs which were randomly selected and each test sample was marked with numbers. As mentioned before, since IES LM-80-08 recommends using 70\% luminary maintenance as standard approach to measure luminary life time, it was decided to select failure criteria as $70 \%$ for this study. Hence as shown in equation 1 in order to find $\mathrm{MTTF}_{\mathrm{T}, 70 \%}$, scaling factor $A$ and the activation energy $\Delta H$ for relevant HBLED samples should be investigated. Furthermore corresponding absolute temperature $T$ should be explored under normal HBLED drive current $\left(I_{H}\right)$ when the failure process takes place under its own constant current driver.

It was decided to use external current source to drive HBLEDs during the study without using its own constant current driver mainly because it may affect the proper controlling of junction temperature during the study. On the other hand, when measure the potential difference across HBLED, and investigating the intensity variations under stress conditions, self junction heating by the bias current must be reduced as much as possible. Such measuring current should be set to minimum so that it only biases the HBLED junction to prevent self junction heating [11]. This measuring current $\left(I_{M}\right)$ value chosen from the experimentally generated V-I characteristics curve which was just above the knee current. For that the forward current through the HBLED was observed while changing the voltage across the DUT and the test was carried out in the room temperature of $23{ }^{\circ} \mathrm{C}$.

In order to investigate the thermal steady state or sufficient heating time determination for HBLEDs under measuring current $\left(I_{M}\right)$ at the room temperature of $23{ }^{\circ} \mathrm{C}$, another experiment was conducted to generate HBLED forward voltage drop vs time curve. Therefore the required heating time for this study could be decided, which should be above the required steady state time. As described earlier, in order to generate plot of $V_{\mathrm{D}}$ vs $T$ for equation 7, eight temperature levels were used from the room temperature of $23{ }^{\circ} \mathrm{C}$ to $90{ }^{\circ} \mathrm{C}$ as per the guidance given in JEDEC 51-1 standard [15]. According to prior test results each HBLED was kept for the investigated heating time in a corresponding temperature level while it drives with constant measuring current $\left(I_{M}\right)$, so that the junction \& surrounding were in thermal equilibrium. Heating time duration, current through $\&$ potential difference across the HBLED and the relevant temperature levels were recorded. 
Junction temperature $T$ was determined under normal HBLED drive current $\left(I_{H}\right)$ using a methodology somewhat similar to the method mentioned in JEDEC 51-1 standard [15]. First the HBLED was driven by drive current $\left(I_{H}\right)$ and heated for 600 seconds then reduced the current flow down to the measuring current $\left(I_{M}\right)$ for 10 seconds while recording the potential difference across the HBLED. This experiment was repeated continuously for nine cycles and minimum potential differences during the measuring current $\left(I_{M}\right)$ flow were obtained and an average value was calculated.

In order to find out scaling factor $A$ and the activation energy $\Delta H$, two HBLED samples were subjected to two different temperature levels of $90{ }^{\circ} \mathrm{C}$ and $110{ }^{\circ} \mathrm{C}$ and measured the light output according to specified time intervals. It was assumed that these temperature levels were quiet high hence it will guarantee to accelerate the degradation of light output of HBLEDs. Time to fail under two high stress conditions were obtained by extrapolating $70 \%$ light output level with the help of normalized light output curves for the two high temperature levels. Using those values $\left(\mathrm{MTTF}_{\mathrm{T}, 70 \%}\right.$ $\&$ corresponding $T$ ) and equation 2, two characteristics values $A$ and $\Delta H$ were estimated.

\section{EXPERIMENTAL SETUP}

The junction temperature has to be determined under normal HBLED drive current $\left(I_{H}\right)$ which was the current driven by its own constant current driver. This $I_{H}$ current was experimentally measured and found to be $310 \mathrm{~mA}$. As mentioned before, all the required test currents were generated using a commercially available current source; Electronic Load Array 3711A. For voltage and current measurements, a 6.5 digit precision FLUKE 8846 A multimeter and a FLUKE 187 digital multimeter were used respectively. The schematic of measuring setup is shown in figure 1(a) and figure 1(b) shows a photograph taken while conducting the experiment to generate V-I characteristics of HBLED.
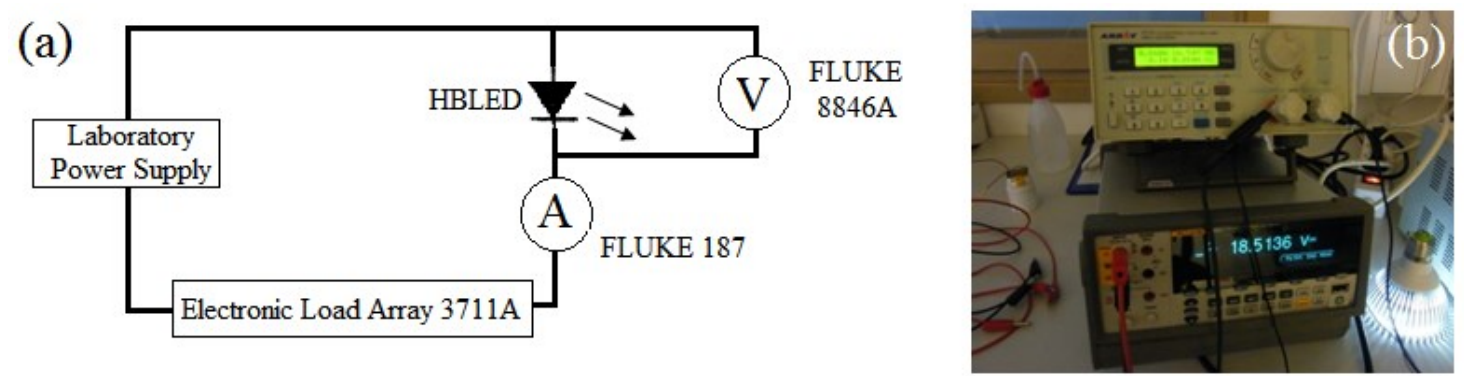

Figure 1. Measurement setup (a) schematic of the setup, (b) a photograph of the setup.

A UMEGA SNOL 67/350 laboratory oven was used to test the HBLEDs at different temperature levels. The oven was set to its maximum heating speed so that all the tested samples were subjected to constant and stable temperature levels throughout the experiment. It was assumed that the temperature inside the oven is uniformly distributed. It was further assumed that the junction temperature is same as the ambient temperature when the HBLED is in thermal equilibrium with its surrounding.

Light output of HBLED was measured using CEM DT-1300 Handheld Digital Lux Meter and the light measuring setup is shown in figure 2 . Well enclosed setup as shown in figure 2(a) \& 2(b) was used to measure light output so that disturbances from surrounding light was minimized. Special positioning marks on shell, holder, light meter and measuring setup were placed to put the test samples in the same angle for every measurement. 

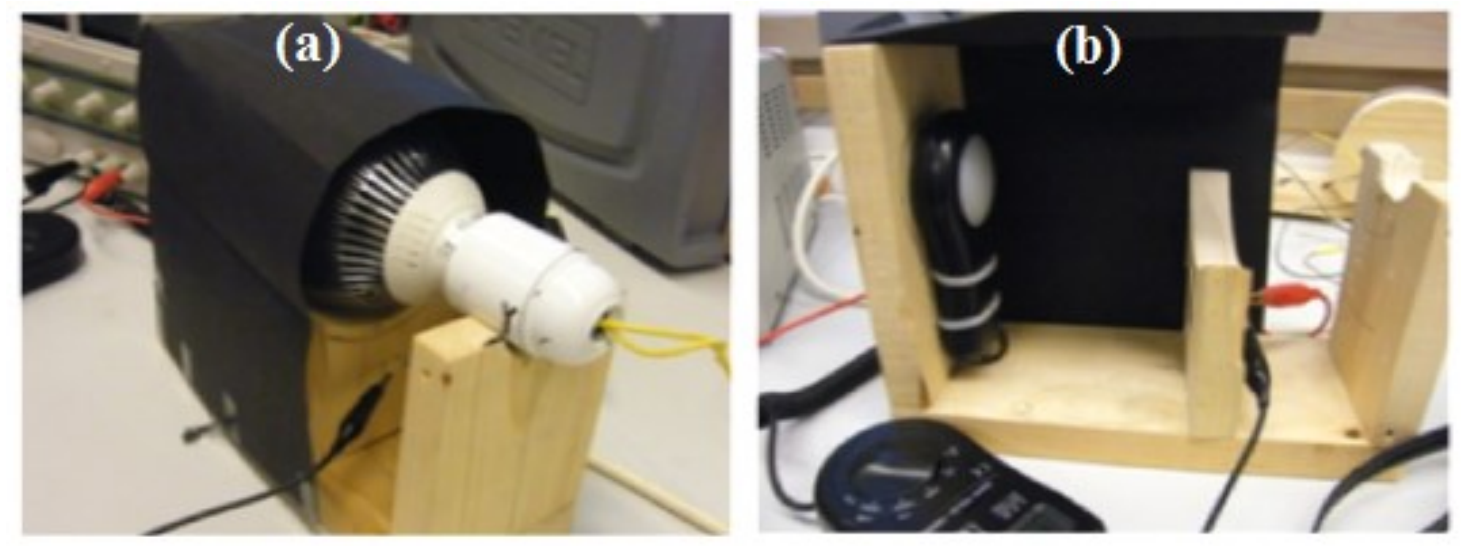

Figure 2. Light measuring setup (a) outer look of the setup, (b) inside view of the setup.

\section{RESULTS AND ANALYSIS}

The respective measured forward current $\left(I_{D}\right)$ through, while changing the forward voltage across the tested HBLED $\left(V_{D}\right)$ at room temperature $\left(23^{\circ} \mathrm{C}\right)$ is given in table 1 in order to extract a suitable measuring current required for this study. This measuring current $\left(I_{M}\right)$ value was chosen as $10 \mathrm{~mA}$ from the V-I characteristics curve shown in figure 3 which is just above the knee current.

Table 1. HBLED forward voltage and corresponding current measured at $23{ }^{\circ} \mathrm{C}$.

\begin{tabular}{|c|c|c|c|}
\hline $\mathbf{V}_{\mathbf{D}}(\mathbf{V})$ & $\mathbf{I}_{\mathbf{D}}(\mathbf{m A})$ & $\mathbf{V}_{\mathbf{D}}(\mathbf{V})$ & $\mathbf{I}_{\mathbf{D}}(\mathbf{m A} \mathbf{A})$ \\
\hline 14.23 & 0.00 & 18.95 & 12.60 \\
\hline 15.05 & 0.00 & 19.04 & 16.10 \\
\hline 15.17 & 0.00 & 19.13 & 17.38 \\
\hline 15.87 & 0.00 & 19.23 & 22.40 \\
\hline 16.33 & 0.00 & 19.32 & 27.18 \\
\hline 17.03 & 0.12 & 19.41 & 29.17 \\
\hline 17.36 & 0.23 & 19.51 & 33.48 \\
\hline 17.45 & 0.35 & 19.60 & 37.33 \\
\hline 17.55 & 0.47 & 19.69 & 41.18 \\
\hline 17.64 & 0.58 & 19.79 & 47.25 \\
\hline 17.73 & 0.70 & 19.88 & 55.07 \\
\hline 17.83 & 0.93 & 20.07 & 64.87 \\
\hline 18.01 & 1.52 & 20.25 & 79.57 \\
\hline 18.11 & 2.10 & 20.35 & 86.68 \\
\hline 18.20 & 2.80 & 20.44 & 91.58 \\
\hline 18.29 & 3.50 & 20.53 & 99.98 \\
\hline 18.39 & 4.20 & 20.63 & 106.87 \\
\hline 18.57 & 6.07 & 20.72 & 120.75 \\
\hline 18.67 & 7.23 & 20.81 & 131.13 \\
\hline 18.85 & 10.38 & - & - \\
\hline
\end{tabular}




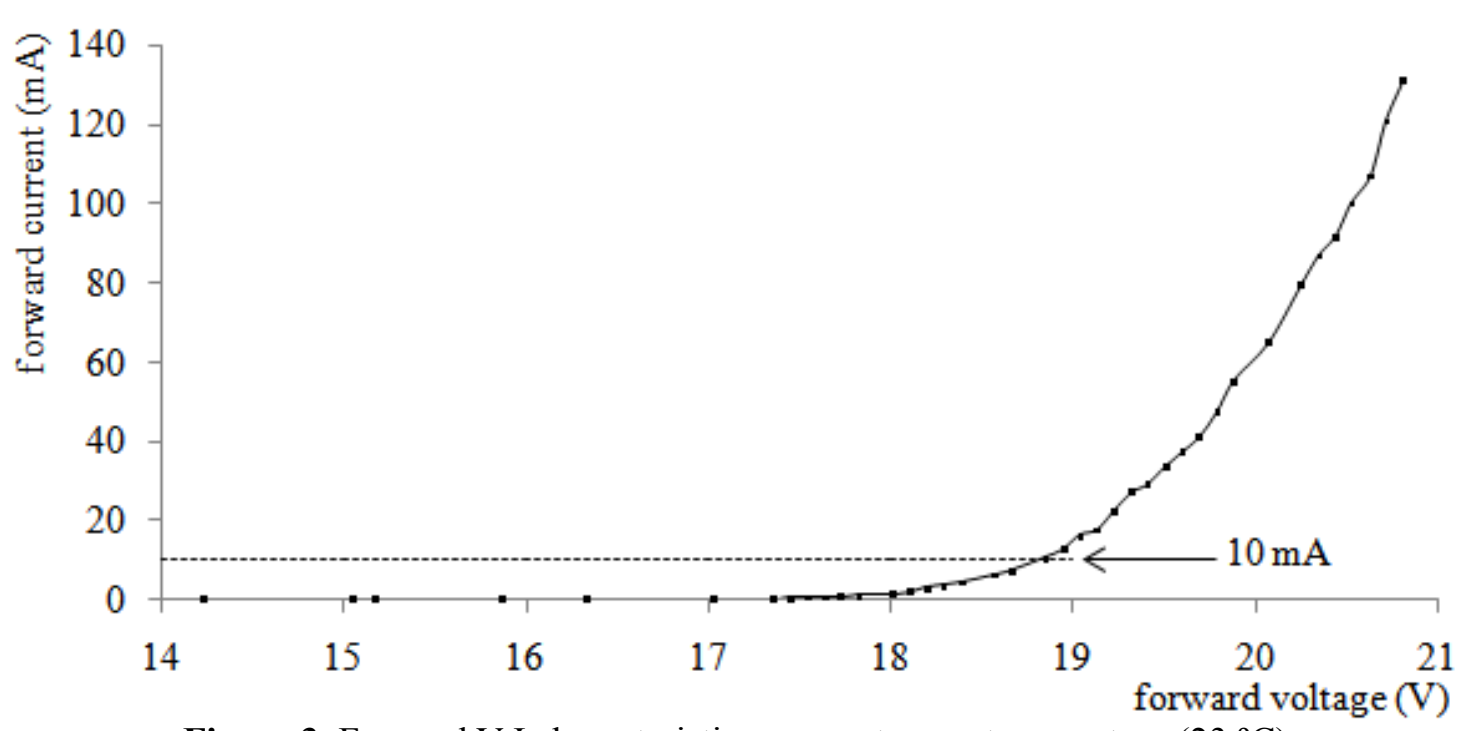

Figure 3. Forward V-I characteristics curve at room temperature $\left(23^{\circ} \mathrm{C}\right)$.

Table 2 indicates the recorded forward voltage drop across HBLED $\left(V_{D}\right)$ at $23{ }^{\circ} \mathrm{C}$ for an hour long test while driving the HBLED with $10 \mathrm{~mA}$ current $\left(I_{M}\right)$. Figure 4 shows the generated HBLED forward voltage drop vs time curve. Even though the ambient temperature and driving current kept constant for this experiment, forward voltage drop was gradually increased up to a certain level with respect to time and after approximately 25 minutes; it was saturated as can be seen in figure 4 . Therefore it was decided to consider 30 minutes as the sufficient heating time required.

Table 2. Forward voltage drop across $\left(V_{D}\right)$ at $23^{\circ} \mathrm{C}$ with constant $10 \mathrm{~mA}$ driving current.

\begin{tabular}{|c|c|c|c|c|c|c|c|c|c|c|c|c|c|c|c|}
\hline Time (minutes) & 0 & 2 & 3 & 5 & 10 & 15 & 20 & 25 & 30 & 35 & 41 & 45 & 50 & 55 & 60 \\
\hline $\mathbf{V}_{\mathrm{D}}(\mathrm{C}$ & $\begin{array}{l}0 \\
n \\
\infty \\
\infty\end{array}$ & $\begin{array}{l}\vec{\infty} \\
\infty \\
\infty\end{array}$ & $\begin{array}{l}\infty \\
\infty \\
\infty \\
\infty\end{array}$ & $\begin{array}{l}\Delta \\
\infty \\
\infty\end{array}$ & $\begin{array}{l}\infty \\
\stackrel{0}{0} \\
\infty\end{array}$ & $\begin{array}{l}\infty \\
\stackrel{\infty}{0} \\
\infty\end{array}$ & $\begin{array}{l}2 \\
\infty \\
\infty\end{array}$ & $\begin{array}{l}2 \\
\infty \\
\infty\end{array}$ & $\begin{array}{l}2 \\
\infty\end{array}$ & $\begin{array}{l}\partial \\
\infty \\
\infty\end{array}$ & $\begin{array}{l}2 \\
\infty \\
\infty\end{array}$ & $\begin{array}{l}\stackrel{\partial}{\infty} \\
\infty\end{array}$ & $\begin{array}{l}2 \\
\infty \\
\infty\end{array}$ & $\begin{array}{l}2 \\
\infty \\
\infty\end{array}$ & $\begin{array}{l}2 \\
\infty \\
\infty\end{array}$ \\
\hline
\end{tabular}

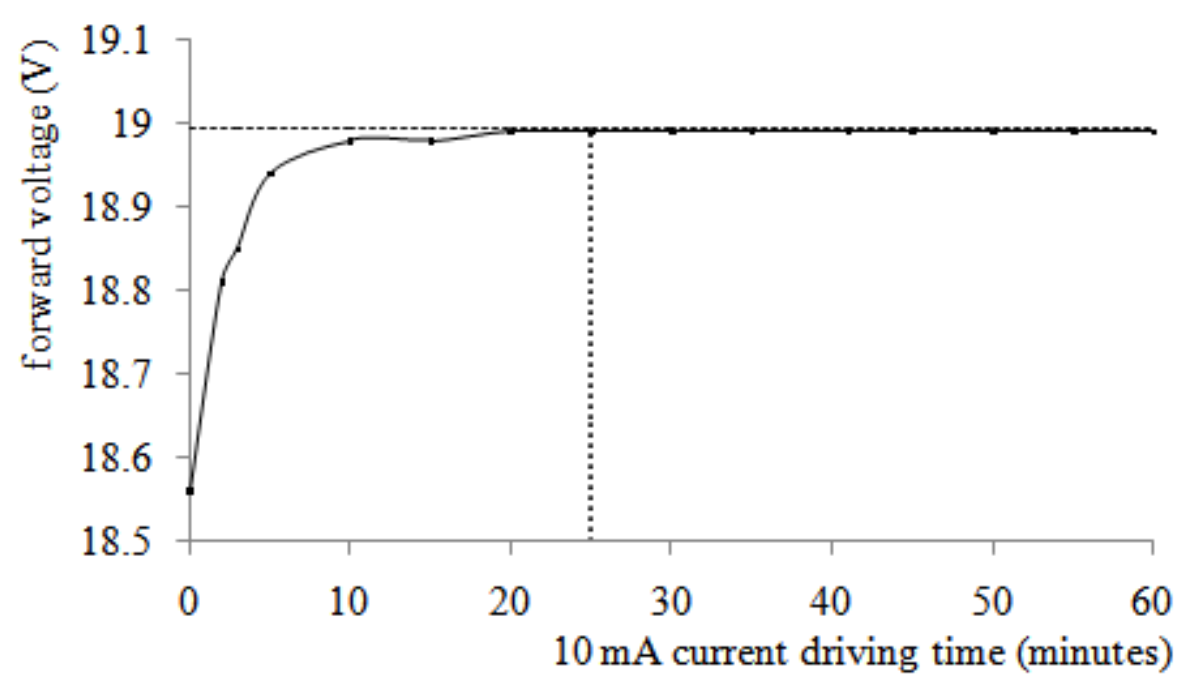

Figure 4. Forward voltage drop vs time curve at $23{ }^{\circ} \mathrm{C}$ with constant $10 \mathrm{~mA}$ driving current.

Table 3 shows the recorded forward voltage drop $\left(V_{D}\right)$ under eight different package temperature levels after drove the each HBLED sample with $10 \mathrm{~mA}$ measuring current for 30 minutes so that each sample was at its thermal steady state. Figure 5 indicates the linear behavior between $V_{\mathrm{D}}$ and $T$ as predicted by equation 7 . Therefore in order to find junction temperature under the normal usage of HBLED, equation 8 can be used which was extracted from the figure 5 by feeding the corresponding forward voltage drop.

$$
T_{\text {junction }}=-102.894 \times V_{\text {forward }}+1942.329
$$


Table 3. Recorded forward voltage drop after drove HBLED at $10 \mathrm{~mA}$ for 30 minutes.

\begin{tabular}{|c|c|}
\hline Package temperature $\left({ }^{\circ} \mathrm{C}\right)$ & Forward voltage $\mathbf{V}_{\mathbf{D}}(\mathbf{V})$ \\
\hline 23 & 18.6584 \\
\hline 30 & 18.5800 \\
\hline 40 & 18.4815 \\
\hline 50 & 18.4012 \\
\hline 60 & 18.2916 \\
\hline 70 & 18.1978 \\
\hline 80 & 18.0922 \\
\hline 90 & 18.0074 \\
\hline
\end{tabular}

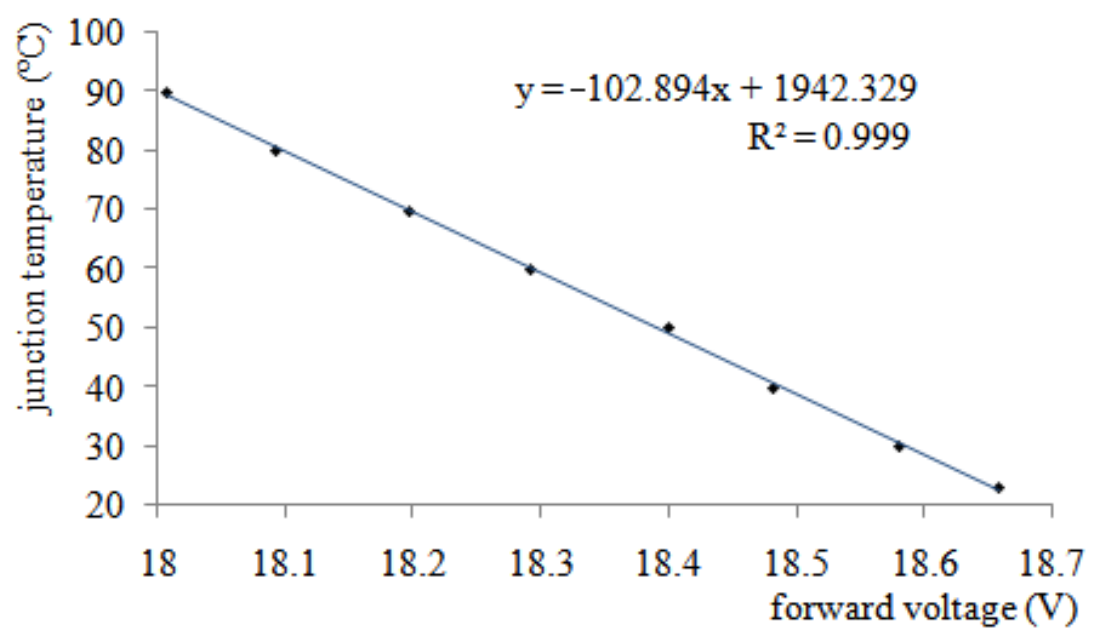

Figure 5. Junction temperature vs forward voltage drop for tested HBLED.

Figure 6 shows the graphical overview of the data recorded from the experiment carried out in order to determine the forward voltage drop under the junction temperature of HBLED in normal use. Figure 6 indicates the measured forward voltage drop when HBLED driven by drive current 310 $\mathrm{mA}\left(I_{H}\right)$ for 600 seconds followed by measuring current $10 \mathrm{~mA}\left(I_{M}\right)$ for 10 seconds and repeated continuously for nine cycles. The lowest forward potential drop values across HBLED at each cycle extracted from this experiment are given in table 4.

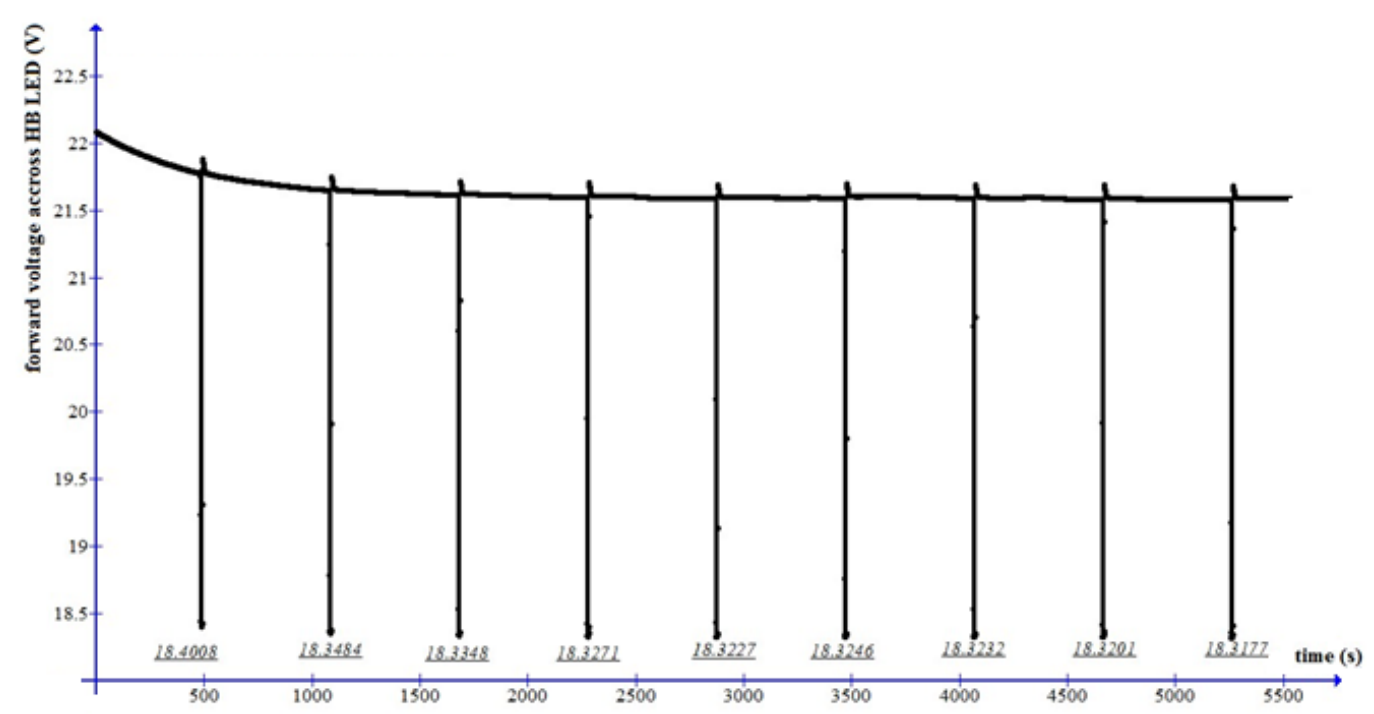

Figure 6. Forward voltage variation with $310 \mathrm{~mA}$ drive current and $10 \mathrm{~mA}$ measuring current.

According to the data given in table 4 , the average forward voltage drop $\left(V_{\text {forward }}\right)$ is $18.3355 \mathrm{~V}$. Hence the relevant junction temperature could be calculated using the equation 8 and it is found to be $55.72{ }^{\circ} \mathrm{C}$. 
Table 4. Lowest forward potential drop across HBLED with $10 \mathrm{~mA}$ measuring current.

\begin{tabular}{|c|c|c|c|c|c|c|c|c|c|}
\hline \multicolumn{2}{|c|}{ Test cycle number } \\
\hline $1^{\text {st }}$ & $2^{\text {nd }}$ & $3^{\text {rd }}$ & $4^{\text {th }}$ & $5^{\text {th }}$ & $6^{\text {th }}$ & $7^{\text {th }}$ & $8^{\text {th }}$ & $9^{\text {th }}$ \\
\hline \multicolumn{8}{|c|}{$V_{\text {forward }}(\mathbf{V})$} \\
\hline 18.4008 & 18.3484 & 18.3348 & 18.3271 & 18.3227 & 18.3246 & 18.3232 & 18.3201 & 18.3177 \\
\hline
\end{tabular}

Tabulated data for the experiment carried out for two HBLED samples under two stress levels of 90 ${ }^{\circ} \mathrm{C}$ and $110^{\circ} \mathrm{C}$ are shown in table 5. Corresponding normalized light outputs for each stress level were calculated and plotted against time as shown in figure 7.

Table 5. Light output and normalized output against time for $90^{\circ} \mathrm{C} \& 110^{\circ} \mathrm{C}$ stress conditions.

\begin{tabular}{|c|c|c|c|c|}
\hline \multirow{2}{*}{ Time (hrs) } & \multicolumn{2}{|c|}{ Light output (Lux) } & \multicolumn{2}{c|}{ Normalized output (\%) } \\
\cline { 2 - 5 } & for $\mathbf{9 0}^{\circ} \mathbf{C}$ & $\mathbf{1 1 0}^{\circ} \mathbf{C}$ & for 90 ${ }^{\mathbf{C}}$ & $\mathbf{1 1 0}^{\mathbf{}} \mathbf{C}$ \\
\hline 0 & 345 & 886 & 100 & 100 \\
\hline 1 & 321 & 806 & 93 & 91 \\
\hline 2 & 297 & 753 & 86 & 85 \\
\hline 3 & 286 & 717 & 83 & 81 \\
\hline 4 & 279 & 701 & 81 & 79 \\
\hline 5 & 273 & 682 & 79 & 77 \\
\hline 6 & 269 & 664 & 78 & 75 \\
\hline 7 & 268 & 655 & 78 & 74 \\
\hline 8 & 266 & 646 & 77 & 73 \\
\hline 9 & 262 & 637 & 76 & 72 \\
\hline 10 & 259 & 629 & 75 & 71 \\
\hline 12 & 255 & 623 & 74 & 70 \\
\hline 16 & 253 & 603 & 73 & 68 \\
\hline 22 & 252 & 575 & 73 & 65 \\
\hline 34 & 250 & - & 72 & - \\
\hline 46 & 248 & - & 72 & - \\
\hline 58 & 246 & - & 71 & - \\
\hline 70 & 245 & - & 71 & - \\
\hline 82 & 243 & - & 70 & - \\
\hline 94 & 242 & - & 70 & - \\
\hline 106 & 241 & - & 70 & - \\
\hline 118 & 239 & - & 69 & - \\
\hline & & & & \\
\hline
\end{tabular}

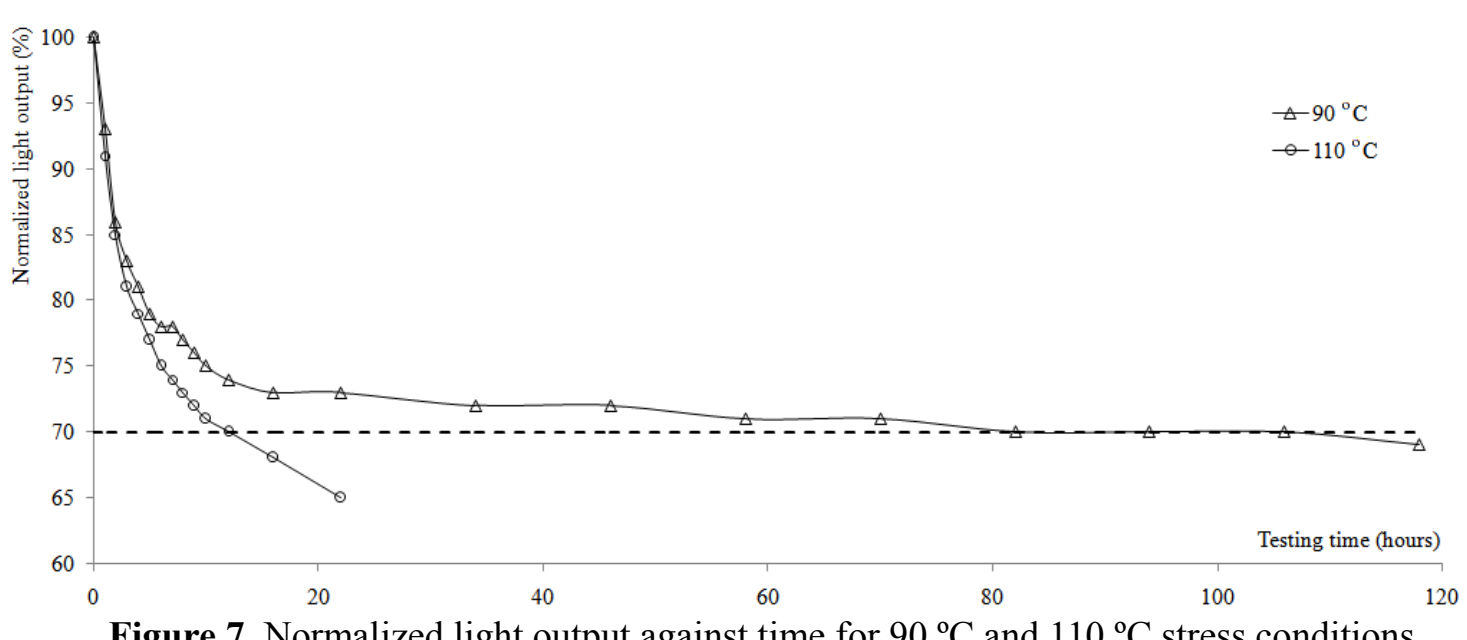

Figure 7. Normalized light output against time for $90^{\circ} \mathrm{C}$ and $110^{\circ} \mathrm{C}$ stress conditions.

As explained before these normalized data were used to extract corresponding time to reach the predefined failure criteria of $70 \%$ under above mentioned two stress levels and those values were found to be 105.86 hours \& 11.89 hours for $\mathrm{MTTF}_{90,70 \%}$ \& $\mathrm{MTTF}_{110,70 \%}$ respectively. By 
feeding these data into the equation 2, activation energy $\Delta H$ and scaling factor $A$ were calculated as $1.31 \mathrm{eV}$ and $6.86 \times 10^{-17}$ hours respectively.

Hence required parametric information in order to apply Arrhenius Acceleration Model as given by equation 2 , and to calculate the life time (luminary life) under $70 \%$ failure criteria in normal use can be tabulated as shown in table 6 . Therefore equation 2 can rewrite with these information as shown in equation 9.

Table 6. Parametric information for Arrhenius Acceleration Model.

\begin{tabular}{|l|l|}
\hline Variable & Parametric value \\
\hline Activation energy $(\Delta H)$ & $1.31 \pm 0.071 \mathrm{eV}$ \\
\hline Scaling factor $(A)$ & $6.86 \times 10^{-17}$ hours \\
\hline Boltzmann's constant $(k)$ & $8.617 \times 10^{-5} \mathrm{evK}^{-1}$ \\
\hline Absolute junction temperature in normal use $(T)$ & $55.72^{\circ} \mathrm{C}(328.72 \mathrm{~K})$ \\
\hline
\end{tabular}

$$
\operatorname{MTTF}_{T, 70 \%}=6.86 \times 10^{-17} e^{\left(\frac{1.31}{8.617 \times 10^{-5} \times(273+55.72)}\right)}
$$

Hence by solving the equation 9 , the life time (luminary life) under $70 \%$ failure criteria in normal use was found to be 8,344 hours.

\section{DISCUSSION}

It is a general question that, "how many hours of useful light provide by a HBLED with predefine luminary maintenance?". It is understandable that a longer lifetime of HBLEDs may provide immediate savings on bulb replacement costs, and easy to justify the higher initial cost. On the other hand different manufacturers stated useful life time of HBLEDs by following their own methodologies and, most of these were time consuming. Even IES LM-80-08 standard requires HBLEDs to be driven for a minimum of 6,000 hours and data collected at least every 1,000 hours [3]. Furthermore longer time consumption for evaluation of luminary life of HBLEDs may not useful in mass production process of HBLED bulbs.

The study demonstrates the possibility of applying Arrhenius Acceleration Model to determine the life time estimation of 1-W HBLEDs with the modeling parameter as the junction temperature with a significant testing time reduction. Two stress levels were selected as $90{ }^{\circ} \mathrm{C}$ and $110{ }^{\circ} \mathrm{C}$ and as recommended by IES LM-80-08 standard, 70\% luminary maintenance was considered as the failure criterion for this study [3].

According to the data given in table 4 , the average forward voltage drop $\left(V_{\text {forward }}\right)$ is 18.3355 $\mathrm{V}$. Hence the relevant junction temperature was calculated using the equation 8 and it is found to be $55.72{ }^{\circ} \mathrm{C}$. Equation 8 shows that the junction temperature and forward voltage across HBLED having a linear relationship, which is believe to be valid for limited range of temperature. The regression coefficient for this experimentally generated expression is 0.999 which reveals how the theory matches with the data at least over $23{ }^{\circ} \mathrm{C}$ to $90{ }^{\circ} \mathrm{C}$ range since it is having a linear relationship.

It is believe that temperature levels used for two stress levels in this study were well beyond the normal junction temperature. This was justified since the junction temperature was experimentally investigated as the $55.72^{\circ} \mathrm{C}$. Furthermore figure 8 shows two thermal pictures taken while a commercially available HBLED bulb comprised with 7 HBLED chips under normal use. It also demonstrates the validity of the junction temperature calculated in this study, even though they show the surface temperature of those HBLEDs. 

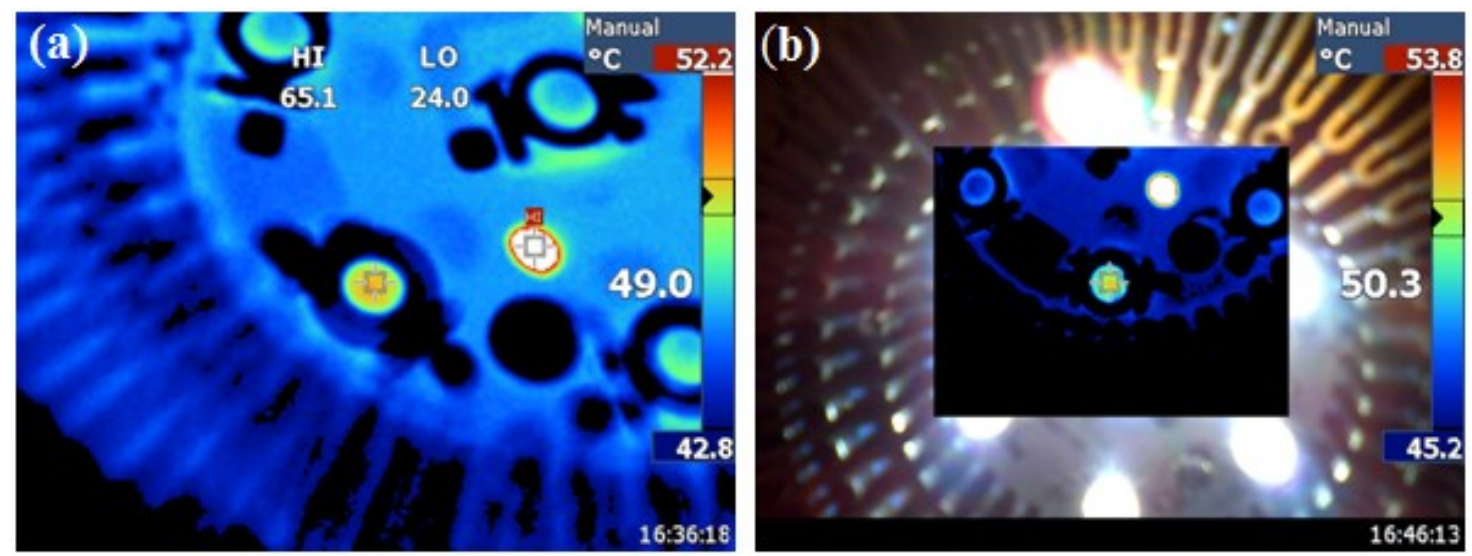

Figure 8. Thermal image of HBLEDs without epoxy lens.

Initially this experiment was design complaint with JEDEC 51-1 standard [15]. But because of Electronic Load Array 3711A limitations, the experiment could not carried out exactly according to the standard. According to the standard the potential difference across the HBLED has to measure within $50 \mu \mathrm{s}$ after removing the drive (heating) current, $I_{H}$ and applying the measuring current, $I_{M}$. However the electronic load array which was used in this study as a constant current source did not comprises this capability. It was noted that there is a minimum of $200 \mathrm{~ms}$ time required to have each transition between those two current levels and the minimum set time of the Electronic Load Array 3711 A is one second. On the other hand, when determined the junction temperature under normal conditions, the heat flowing from HBLED to its case is the only concern. Therefore, the heating time for drive current $I_{H}$ was taken as $600 \mathrm{~s}$. However, as suggested by the JEDEC 51-1 standard [15] this heating time would be few seconds. Hence for better result the heating time was taken as 600s. This extra time does not reduce the accuracy of measurement instead it increases the likelihood of steady-state condition occurrence. When scrutinizing graph shown in figure 6 , it is clearly shown that all minimum voltages are more or less equal. This is a great clue that HBLED became to thermal steady-state during the test.

On the other hand junction temperature was the only factor which considered for this study as the degradation factor. Even though commercially available HBLED bulbs are well enclosed, they are sensible to humidity variations slightly as well. Further, it is believe that a fluctuation of current through HBLEDs and cyclic effects of operations also could play an impact on luminary degradation.

\section{CONCLUSION}

Randomly selected brandnew 1-W HBLEDs were used for this study while two of them were subjected to accelerated life test for luminary life time estimation. The acceleration model applied for this study was Arrhenius Acceleration Model and modeling parameter was junction temperature of the HBLED. Stress levels were to be $90{ }^{\circ} \mathrm{C}$ and $110^{\circ} \mathrm{C}$ and for each of above test cases, the light output was met the failure criterion which was the $70 \%$ luminance maintenance. The activation energy $(\Delta H)$ and the scaling factor $(A)$ for the tested HBLED family were found to be $1.31 \pm 0.071$ $\mathrm{eV}$ and $6.86 \times 10^{-17}$ hours respectively. The junction temperature under normal operation found to be $55.72^{\circ} \mathrm{C}$. Hence it can be concluded that by considering junction temperature of the HBLED as the luminary depreciation parameter, $70 \%$ luminary life time of $1-W$ HBLEDs as 8,344 hours.

\section{Acknowledgements}

Financial assistance received from the EURECA (European Union Research and Education Collaboration with Asia) Project, is acknowledged. Department of Information Technology, University of Turku and Department of Physics, University of Colombo are acknowledged for providing facilities and opportunities in numerous ways. Assistance provided by Prof. Aulis Tuominen is highly acknowledged. 


\section{References}

[1] S. H. Lim, et al. Light and Lighting Conference with Special Emphasis on LEDs and Solid State Lighting, Budapest, 27-29 May 2009.

[2] R. Karlicek, "High-power LED packaging." Conference on Lasers and Electro-Optics. Optical Society of America, 2005, pp 337-339.

[3] IES Testing Procedures Committee. "IES LM-80-08, IES Approved Method for Measuring Lumen Maintenance or LED Light Sources, New York." Illuminating Engineering Society of North America (2008).

[4] M. Ott, "Capabilities and reliability of LEDs and laser diodes." Internal NASA Parts and Packaging Publication (1996).

[5] Y. Gu, N. Narendran, and J. P. Freyssinier, "White LED performance." Optical Science and Technology, the SPIE $49^{\text {th }}$ Annual Meeting. International Society for Optics and Photonics, 2004, pp 119-124.

[6] J. S. Jeong, J. K. Jung, and S. D. Park, "Reliability improvement of InGaN LED backlight module by accelerated life test (ALT) and screen policy of potential leakage LED." Microelectronics Reliability 48.8 (2008): 1216-1220.

[7] C. M. Tan, et al. "Humidity effect on the degradation of packaged ultra-bright white LEDs." Electronics Packaging Technology Conference, 2008. EPTC 2008. 10 ${ }^{\text {th }}$. IEEE, 2008, pp 923928.

[8] T. Yanagisawa, and T. Kojima, "Long-term accelerated current operation of white lightemitting diodes." Journal of luminescence 114.1 (2005): 39-42.

[9] E. S. Schlig, "Electrothermal considerations in display applications of light-emitting diodes." Electron Devices, IEEE Transactions on 19.7 (1972): 847-851.

[10] N. Narendran, et al. "Long-term performance of white LEDs and systems." Proceedings of First International Conference on White LEDs and Solid State Lighting. 2007, pp 174-179.

[11] Sematech, N. I. S. T. "Engineering statistics handbook." (2006).

[12] K. Pommer, "Reliability Study of GaAs, 63P. 37 LED'S." Reliability Physics Symposium, 1975. 13th Annual. IEEE, 1975, pp 200-206.

[13]L. Trevisanello, et al. "Accelerated life test of high brightness light emitting diodes." Device and Materials Reliability, IEEE Transactions on 8.2 (2008): 304-311.

[14] E. Hong, and N. Nadarajah, "A method for projecting useful life of LED lighting systems." Optical Science and Technology, SPIE's $48^{\text {th }}$ Annual Meeting. International Society for Optics and Photonics, 2004, pp 93-99.

[15] STANDARD, Integrated Circuits Thermal Measurement Method - Electrical Test Method (Single Semiconductor Device), EIA/JESD51-1, December 1995. 